\title{
Effective therapeutic communication knowledge of professional dental program students
}

\author{
Meity Karina Sari*,Gilang Yubiliana*,Netty Suryani* \\ *Department of Public Health Faculty Of Dentistry, University of Padjadjaran
}

\begin{abstract}
Introduction: World Health Organization (WHO) declared the ultimate goal of medical education is to produce the five-star doctor, that doctor as a care provider, decision maker, manager, community leader, and communicator. Effective therapeutic communication can be learned and trained mainly on the professional program students. The purpose of this research was to obtain the data and information about effective therapeutic knowledge of professional communication dental program students. Methods: This research was a descriptive research with survey techniques. The sampling methods was simple random sampling from the questionnaire on 132 respondents. Results: The results of this research from the questionnaire shows the average level of effective therapeutic communication professional knowledge at student's program in Dental Hospital Faculty of Dentistry Universitas Padjadjaran is $85 \%, 56 \%$ and classified as good level. Conclusion: Effective therapeutic knowledge of professional communication dental program students relatively good.
\end{abstract}

Keywords: Dental and Oral Hospital, Faculty of Dentistry, Padjadjaran University, Effective Therapeutic Communication, Knowledge

\section{INTRODUCTION}

Data from the Indonesian Medical Disciplinary Honorary Council (MKDKI), there were 127 complaints of violation of discipline by physicians or dentists up to March 2011. Approximately $80 \%$ of the figures fueled by the lack of communication (Dinkes DKI). ${ }^{1}$ Another surprising thing is the fact that more than one hundred thousand citizens of Indonesia went to Singapore, Malaysia, and China Ghuang Zou for treatment annually. The data on the number of foreign exchange in 2006 showed that a total of US $\$ 600$ million went into hospital abroad annually.
National Health care Group General Manager International Business Development Unit (NHGIBDU) revealed that as many as 50\% of international patients who went to Singapore are Indonesian. It is most often the beginning of the problem is the weakness of communication between doctor and patient or between the hospitals with the patient. According to General Manager NHGIBDU, patients seek treatment in Singapore revealed satisfaction, because they are able to consult with a doctor up to 1 hour. Unlike in Indonesia, patients consult a doctor very briefly.

The data are from MKDKI, one of the main factors that may cause an increase in the need of 
medical treatment abroad is the relationship of how is the communication between the doctorpatient in Indonesia is unfavorable. The way the doctor-patient communication in Indonesia may be far less than the doctors abroad, however the medically ability of Indonesian doctors do not lose to the overseas doctors. In addition, patients and physicians in our country use the same language. With the same language applied should make it easier to establish communication, displaying empathy and so forth.

Physician skills in conveying the information seems to be the key in these situations. If the doctor does not communicate well, then there is a misconception that could be culminated in complaints by patients either to MKDKI or directly to the court. Communication is an integral part of any health administrative functions. Therefore, communication is referred to as blood flow within an organization. ${ }^{2}$

The facts above proved that how weak the doctor-patient communication in Indonesia. The weakness of communication between doctorpatient failed to build a good relations between the doctor-patient. Seeing such conditions and the complexity of the problems of our medical world, it seems to be difficult to solve. But this is not an excuse to be unable to improve the quality of medicine in Indonesia. In future, a doctor should be completely embedded that a communication link with the patients is an absolute thing to be aware of, to consider about communication education in the curriculum of medical education.

World Health Organization (WHO) declared the ultimate goal of medical education is to produce the five-star doctor, the doctor as a care provider, decision maker, manager, community leader, and communicator. Without good communication skills, clinical knowledge and other skills can be ineffective. Dental Hospital Faculty of Dentistry Universitas Padjadjaran is one of the teaching hospitals as a place where students of professional programs implementing effective therapeutic communication that has been gained in the pre-clinic.

Effective therapeutic communication is a thing that can be learned and practiced. Therefore, students of professional programs already interested to learn about the effective communication and apply them in their daily practices. Based on these descriptions the author aims to learn more about how knowledge of effective therapeutic communication in the professional program student of dentistry at the Dental Hospital Faculty of Dentistry Universitas Padjadjaran.

\section{METHODS}

The type of this research is a descriptive research with survey techniques. Descriptive study conducted on a number of objects within a certain period and aims to make an assessment of the condition and operation of a program in the present, then the results are used to compile the program improvement plan. The population in this study were all students of 2007 and 2008 who are undergoing dental profession in the Dental Hospital Faculty of Dentistry Universitas Padjadjaran. Samples were selected by simple random sampling technique.

Based on the data obtained, in 2011-2012 there were 196 students of 2007 and 2008 who are undergoing dental profession in the Dental Hospital Faculty of Dentistry Universitas Padjadjaran who will be the population in this study. The formula used to determine the number of sample if the study sample population less than 10,000 subjects referred to Budiharto. ${ }^{3}$ The number of samples in this study was 132 people.

The assessment conducted based on the scope of knowledge. Questions on the questionnaire are given to assess the level of knowledge on effective communication and therapeutic. The correct answer will be given a value of 1 , while the wrong answer will be rated $0 .{ }^{3}$ Data obtained will be presented in a table form. Data obtained processed using a formula referring to Budiharto,2008 with a final result of a percentage. ${ }^{4}$ Results of the assessment will be categorized into good (76-100\%), average $(60-75 \%)$ and less $(<60 \%){ }^{4}$

\section{RESULTS}

The results obtained from questionnaires which is filled by 132 respondents. Respondents were students of profession program faculty of dentistry Universitas Padjadjaran class of 2007 and 2008 who has learned about effective therapeutic 
communication. Before discussing the therapeutic effective communication on profession program student at the Dental Hospital Faculty of Dentistry Universitas Padjadjaran, the authors will describe

Table 1. Characteristics of Respondents by Gender

\begin{tabular}{ccc}
\hline Gender & & Frequency \% \\
\hline Male & 15 & 11.36 \\
Female & 117 & 88.64 \\
\hline Total & 132 & 100 \\
\hline
\end{tabular}

the characteristics of respondents including gender and age. From the table 1, it appears that almost all of the respondents surveyed were

Table 2. Characteristics of Respondents by Age

\begin{tabular}{ccc}
\hline Age & & Frequency $\%$ \\
\hline$<20$ years & 2 & 1.52 \\
$20-22$ years & 117 & 88.64 \\
$23-25$ years & 13 & 9.85 \\
\hline Total & 132 & 100 \\
\hline
\end{tabular}

Table 3. Outcomes Assessment Questionnaire Profession Student Program at the Dental Hospital Faculty of Dentistry, Universitas Padjadjaran

\begin{tabular}{|c|c|c|c|c|}
\hline \multirow{2}{*}{ Question } & \multicolumn{2}{|c|}{ True } & \multicolumn{2}{|c|}{ False } \\
\hline & & $\mathrm{F} \%$ & & $\mathrm{~F} \%$ \\
\hline Definition of doctor-patient communication by the Indonesian Medical Council & 114 & 86.36 & 18 & 13.64 \\
\hline $\begin{array}{l}\text { Definition of effective communication doctor-patient according to the Indonesian Medical } \\
\text { Council }\end{array}$ & 107 & 81.06 & 25 & 18.94 \\
\hline definition of therapeutic communication & 40 & 30.30 & 92 & 69.70 \\
\hline therapeutic communication type & 104 & 78.79 & 28 & 21.21 \\
\hline Directions communication therapeutic & 125 & 94.70 & 7 & 5.30 \\
\hline Purpose of therapeutic communication & 125 & 94.70 & 7 & 5.30 \\
\hline Benefits of effective doctor-patient communication & 131 & 99.24 & 1 & 0.76 \\
\hline approach to communications made in a therapeutic effective communication & 65 & 49.24 & 67 & 50.76 \\
\hline Terms of good communication between doctor-patient & 123 & 93.18 & 9 & 6.82 \\
\hline effective communication Objective & 130 & 98.48 & 2 & 1.52 \\
\hline Phase effective communication session beginning & 68 & 51.52 & 64 & 48.48 \\
\hline collection phase effective communication of information on physicians & 113 & 85.61 & 19 & 14.39 \\
\hline Phase cover effective communication of information on physicians & 108 & 81.82 & 24 & 18.18 \\
\hline Phase build relationships with non-verbal communication & 98 & 74.24 & 34 & 25.76 \\
\hline Patient satisfaction was born because their physician empathy & 127 & 96.21 & 5 & 3.79 \\
\hline Respect for patients' views & 129 & 97.73 & 3 & 2.27 \\
\hline Explaining the diagnosis and treatment options before deciding treatment & 129 & 97.73 & 3 & 2.27 \\
\hline care decision making based on the doctor-patient discussions & 95 & 71.97 & 37 & 28.03 \\
\hline Prevent misunderstandings by instructing the patient to repeat the explanation & 95 & 71.97 & 37 & 28.03 \\
\hline Principles that should be owned in an effective doctor-patient communication & 119 & 90.15 & 13 & 9.85 \\
\hline causes patient discomfort & 121 & 91.67 & 11 & 8.33 \\
\hline $\begin{array}{l}\text { Responding to the stationing of patients in the process of anamnesis an important part in } \\
\text { diagnosing a patient }\end{array}$ & 124 & 93.94 & 8 & 6.06 \\
\hline Principles of therapeutic communication by reducing unnecessary communications & 120 & 90.91 & 12 & 9.09 \\
\hline aspect in establishing communications with emphasis on the relationships among man & 103 & 78.03 & 29 & 21.97 \\
\hline One of the goals of therapeutic communication is to relieve the burden on the patient & 131 & 99.24 & 1 & 0.76 \\
\hline Principles of therapeutic communication with respect & 130 & 98.48 & 2 & 1.52 \\
\hline Communication effective therapeutic use of communication verbal and nonverbal & 127 & 96.21 & 5 & 3.79 \\
\hline $\begin{array}{l}\text { Attitudes that support the effective and therapeutic communication is to actively establish a } \\
\text { conversation }\end{array}$ & 130 & 98.48 & 2 & 1.52 \\
\hline patient comfort will be born when doctors accept patients what their & 130 & 98.48 & 2 & 1.52 \\
\hline aspects that support the success of therapeutic communication is sensitive & 127 & 96.21 & 5 & 3.79 \\
\hline
\end{tabular}


Table 4. Knowledge Level of Effective Therapeutic Communication Program Student Professional In Hospital Dental Faculty of Dentistry, Padjadjaran University

\begin{tabular}{ccc}
\hline Knowledge Level & & Frequency \% \\
\hline Good & 120 & 90.91 \\
Enough & 10 & 7.58 \\
Less & 2 & 1.52 \\
\hline Total & 132 & 100 \\
\hline
\end{tabular}

female were 117 respondents (88.64\%), while the rest are men as much as 15 respondents (11.36\%). Table 2 showed that the majority of respondents surveyed are aged between 20-22 years were 117 respondents $(88.64 \%)$, while the rest are between 23-25 years as many as 15 respondents $(9.85 \%)$, and under 20 years of as much as 2 respondents (1.52\%).

Table 3 showed that the majority of respondents answered correctly questions about one theurapeutic communication purpose is to ease the burden on patients, as many as 131 respondents $(99,24 \%)$. In addition, the table also shows that most respondents answered any questions about the definition of therapeutic communication in the amount of 92 respondents (69.70\%).

Table 4 showed that knowledge of effective therapeutic communication in professional program student at the Hospital Dental Padjadjaran University School of Dentistry of 120 respondents $(90.91 \%)$ with good category, 10 respondents $(7.58 \%)$ with enough categories, and 2 respondents (1.52\%) with less category.

\section{DISCUSSION}

Table 1 the characteristics of respondents by gender, shows that almost all of the respondents surveyed were female were 117 respondents $(88.64 \%)$, while the rest are men as much as 15 respondents (11.36\%). This is because students in the Faculty of Dentistry, Universitas Padjadjaran majority are women. Characteristics of respondents by age, are presented in Table 2. It shows that the majority of respondents surveyed are aged between 20-22 years were 117 respondents $(88.64 \%)$, while those aged between 23-25 years as many as 15 respondents ( $9.85 \%$ ), and under 20 years of as much as 2 respondents (1.52\%). This is because students of 2007 and 2008 had an average age of 20-22 years.

On the question no.1 (Table 3), about the definition of physician-patient communication by the Indonesian Medical Council, the majority of respondents to answer correctly the question, namely the 114 respondents $(86.36 \%)$. On the question no. ${ }^{2}$ (Table 3 ), the majority of respondents able to answer questions about the definition of physician-patient communication are effective according to the Indonesian Medical Council, as many as 107 respondents (81.06\%). The number of respondents who answered correctly questions no. 1 and no. 2 could be due to respondents already understand well the definition of physician-patient communication and effective physician-patient communication.

Question about the definition of therapeutic communication on the question no.3 (Table 3), the majority of respondents were unable to answer correctly, which amounted to 92 respondents $(69.70 \%)$. This is because the respondent does not understand the definition of communication therapy. Respondents also assumed that the definition of therapeutic communication similar with the definition of physician-patient communication. If further investigation, doctorpatient communication are part of the therapeutic communication. It may not have been clearly understood by the respondents, so it requires further explanation to the respondents about the definition of therapeutic communication.

In Table 3, about the types of effective therapeutic communication, number of respondents who answer correctly are :104 respondents $(78.79 \%)$ on the question no.4, 125 respondents $(94.70 \%)$ on the question no.5, and 127 respondents $(96.21 \%)$ on the question no.27. Effective therapeutic communication including interpersonal communication is done in two directions and include verbal and non-verbal communication. This is consistent with the theory presented by Soelarso in 2005 that the communication that occurs during therapeutic transaction is interpersonal communication. ${ }^{4}$ Interpersonalcommunications is thecommunication that occurs between two people or more, can be verbal and nonverbal, this process can occur directly without involving the communication media as a conductor of the message. ${ }^{6}$ Number of respondents who answer correctly 
the question no. 6 of 125 respondents (94.70\%), question no.7 of 131 respondents (99.24\%), question no. 10 many as 130 respondents $(98.48 \%)$, and the question no.25 of 131 respondents (99, $24 \%)$. These questions about the purpose and benefits of effective therapeutic communication. This is in accordance with the purpose and benefits of communication according to the Indonesian Medical Council in 2006, which helps to provide choice in solving the health problems of patients, increase patient confidence, ease the burden on patients, as well as improve the accuracy and supportive.

On the question no.8 (Table 3), the majority of respondents were unable to answer correctly the question, which amounted to 67 respondents $(50.76 \%)$. The question is about the kind of effective approach to therapeutic communication according to the communication style diseases presented by Kurtz in $1998 .{ }^{5}$ This question cannot be answered by the respondents because respondents may not understand the kinds of approaches in an effective therapeutic communication. Question no.11, no.12, no.13 and no.14 (table 4.3), the majority of respondents could correctly answer these questions. Question no.11 can be correctly answered by 68 respondents (51.52\%), question no. 12 by 113 respondents ( $85.61 \%)$, question no. 13 by 108 respondents $(81.82 \%)$, and the question no. 14 by 98 respondents (72.24\%). The questions are about the stages in the application of effective physician-patient communication by the Indonesian Medical Council. There are several stages in the application of effective physicianpatient communication, including stage beginning session, information gathering stage, the stage of building relationships, explanation and planning phase, and the phase of the closing session. The majority of respondents already know about these stages in applying an effective therapeutic communication, such as greeting and introducing themselves at the beginning of the session. In addition, using open and closed questions at the information gathering stage, indicate to the patient at the explanation and planning phase, also use non-verbal communication at the stage of building a relationship.

There are two sessions are important in doctor-patient communication: information gathering session in which there is the history and process of information delivery session. If information is not carried out accurately (including advice, suggestion or motivation and counseling), then the process of information delivery session can be premature.

Anamnesis and treatment planning process requires an effective therapeutic communication to avoid misunderstanding between doctor and patient. It was contained in the question no.17 (table 3) explanation of diagnosis and treatment plan for the patient, can be answered by 129 respondents $(97.73 \%)$. On the question no.18 (table 3) about the decision based on discussions between doctors and their patients, the respondents can answer correctly to these questions, as many as 95 respondents (71.97\%). Question no.19 (table 3) is about the process of history of the patient to repeat the explanation the doctor to avoid misunderstandings. No.19 questions can be answered by 95 respondents (71.97\%). Question 21 (table 3) on the dominant attitude of doctors will result in inconvenience to the patient, can be correctly answered by 121 respondents $(91.67 \%)$. These questions can be answered correctly because the respondent has understood the importance of an effective therapeutic communication in the process of diagnose and treatment planning.

The principles of effective therapeutic communication are empathy, response, mutual respect, active, acceptance, and sensitive. These things are at no.15 questions about liability doctor's empathy for his patients, no. 22 questions about doctors respond to the statement of the patient, as well as questions of mutual respect no.26 on physician and patient. In addition, no.28 questions about a doctor who actively build the conversation in order to realize an effective therapeutic communication, question no.29 on the obligation of physicians accept all the circumstances of the patient, and questions about the doctor no. 30 sensitive to the conditions and patient complaints. The majority of these questions can be answered correctly by the respondents, as many as 127 respondents (96.21\%) on the question no.15, 124 respondents (93.94\%) on the question no.22, 130 respondents $(98.48 \%)$ in question no.26, no. 28 and 29 , and as many as 127 respondents $(96.21 \%)$ on the question no.30. This may be because the respondent has understood the 
principles that must be done to create an effective therapeutic communication. Table 4 shows an overview of effective therapeutic communication knowledge to students in the professional program Dental Hospital Dental School, University of Padjadjaran. Based on the table, indicating that an effective therapeutic communication knowledge to students in the professional program Dental Hospital Faculty of Dentistry, University of Padjadjaran as many as 120 respondents $(90.91 \%)$ had a good knowledge, 10 respondents (7.58\%) have sufficient knowledge, and 2 respondents (1.52\%) have less knowledge. The average level of effective therapeutic communication knowledge to students in the professional program Dental Hospital Dental School, University of Padjadjaran which $85.56 \%$ were classified in either category. This is in accordance with the revelation of the World Health Organization (WHO) is the ultimate goal of medical education is to produce the five-star doctor, the doctor as a care provider, decision maker, manager, community leader, and communicator.

The results of good research on effective therapeutic communication knowledge to students, as well as due to the professional program student has learned about effective therapeutic communication at a lecture in preclinic.

Based on this research, in general, students in the professional program Dental Hospital Dental School, University of Padjadjaran already reached the level of know (know) and understanding (comprehension) of effective therapeutic communication. Good knowledge of classified already expected to be applied and became a behavior that can be applied (application) by the student with his patients. Rogers found knowledge or cognitive domain is very important for the formation of a person's actions, because of the experience and the study was based on the knowledge of behavior will be more lasting than the behavior that is not based on knowledge. ${ }^{7}$

\section{CONCLUSION}

Effective therapeutic knowledge of professional communication dental program students relatively good.

\section{REFERENCES}

1. Goel SL. Health Care System andManagement. Michigan: Deep \& Deep Publications. 2001. p. 83.

2. Budiharto. Health Research Methodology with Example Dental Health Science. Jakarta: EGC. 2008. p. 33

3. Mas'ud, Fuad. Survey of Organizational diagnosis (Concepts and Applications). Semarang: Diponegoro University. 2004.

4. Soelarso H, Soebakti RH, Mufid A. Role of Interpersonal Communication in Health CareDental.Surabaya: Dent J, University Airlanggga. 2005. p. 125-126.

5. Kurtz S, Silverman J, Drapper J. Teaching and Learning Communication Skills in Medicine. Oxon: Radcliffe Medical Press. 1998.

6. Indonesian Medical Council. 2006. Manual Effective Physician-PatientCommunication. Jakarta. 2006. p. 5-25.

7. Notoatmojo. Health BehaviorScience. Jakarta: PT Rineka Reserved. 2010. p. 20-29. 